\title{
Torrential Epistaxis with Symmetrical Facial-skin Ulceration in Sickle-cell Anaemia
}

\author{
F. I. D. KONOTEY-AHULU,* M.B., M.R.C.P., M.R.C.P.GLASG., D.T.M.\&H.
}

Brit. med. F., 1965, 2, 859-860

Epistaxis and skin ulcerations are just two of the protean manifestations of sickle-cell anaemia. Epistaxis is common (Hughes et al., 1940; Wintrobe, 1951), even to the extent of one-third of all patients with a sickle-cell anaemia and a sickle-cell/haemoglobin-C disease (Hook and Cooper, 1958), and can be very severe (Mabayoje, 1956 ; Hook and Cooper, 1958).

Chronic leg ulcers are the commonest skin lesions in sicklecell anaemia. They were described in all the earliest reports on sickle-cell anaemia (Herrick, 1910 ; Washburn, 1910-11 ; Cook and Meyer, 1915 ; Mason, 1922 ; Huck, 1923 ; Steinfield and Klauder, 1927). Elbow ulcers have also been described (Corrigan and Schiller, 1934). The most common site for the appearance of ulcers is the lower third of the leg, particularly on the medial side just above the ankle (McGavack and Nussbaum, 1942), but no area of the skin is really exempt. One-third of the ulcers occur bilaterally (McGavack and Nussbaum, 1942); they are usually discreet and rather punched out, and can be of all sizes. In some cases, as in the one described below, ulcers may be covered with a dry serous or seropurulent crust (Cummer and LaRocco, 1940), and may heal only slowly, leaving a scar which is thin, atrophic, smooth, glossy, unpigmented, and surrounded by a pigmented areola (Steinfield and Klauder, 1927). The histological picture of the ulcer is that of a chronic granuloma (Ormsby and Montgomery, 1954).

The association in a sickle-cell crisis of severe epistaxis with symmetrical facial-skin necrosis has not been described before.

\section{Case Report}

A 16-year-old schoolgirl was admitted very early one morning in January 1961 to Korle Bu Hospital, Accra, with profuse epistaxis which had occurred on and off for the previous week. Facial ulceration was noted about the same time as the epistaxis. She was not in the habit of nose-picking and denied having had recurrent joint pains in the past.

On examination she was undersized for her age, and was breathing through her mouth because of profuse nose-bleeding. There was slight icterus with generalized soft lymphadenopathy. Her temperature was $100^{\circ} \mathrm{F}$. $\left(37.8^{\circ}\right.$ C.), pulse $118 / \mathrm{min}$., B.P. $100 / 60$. The liver was three and the spleen four fingerbreadths palpable, but not tender. The apex beat was not displaced, but a systolic bruit was heard over the whole of the praecordium. The face was covered from the hairline to a horizontal line drawn just beneath the lower lip, and from ear to ear, with symmetrically arranged shallow ulcers, nearly all of which had a dry seropurulent crust. Apart from pallor of her palms and conjunctivae there were no other physical signs.

Investigations.-Haematocrit $23 \%$; sickling + ; electrophoresis SS ; platelets 150,000/c.mm. ; leucocytes 13,000/c.mm. (polymorphs $62 \%$, lymphocytes $35 \%$ ) ; blood film normal ; no malaria parasites seen. Widal: $\mathrm{O}, 1 / 80 ; \mathrm{H}$, nil ; blood culture negative. Serum bilirubin $1 \mathrm{mg} . / 100 \mathrm{ml}$. Urine, N.A.D. Stools, ova of strongyloides seen.

- Research Fellow, Renal Unit, Royal Free Hospital, London. Commonwealth Scholar. Formerly Medical Officer at Korle Bu Hospital, Accra, Ghana. Present address: Ghana Medical School, Accra.
Epistaxis continued intermittently for a further 36 hours. An estimate of total blood loss was between 300 and $500 \mathrm{ml}$., but the haematocrit reading remained at $22 \%$. Pyrexia remained between 99 and $101^{\circ}$ F. ( 37.2 and $38.3^{\circ}$ C.). After the patient had been one week in hospital the crusts on the face began to peel off, leaving a raw, red, wet base. Nothing was used on the ulcers. Meanwhile a hot fluctuant swelling of the left elbow appeared; this later developed into an abscess, pus from which grew Salmonella typh $i$, with no change in the Widal reaction. $X$-ray examination revealed underlying osteomyelitis. After two months her facial ulcers had healed (see Photograph), leaving scars which were thin, atrophic, pliable, smooth, glossy, unpigmented, and surrounded by a pigmented areola-similar to the description given by Steinfield and Klauder (1927). The symmetry of these scars was remarkable. While the patient became apyrexial on $0.5 \mathrm{~g}$. of chloramphenicol daily for two weeks, ulcers developed on both legs just above the malleoli medially. She was given ferrous gluconate and vitamins, and an eight-day course of dithiazanine for the strongyloides.

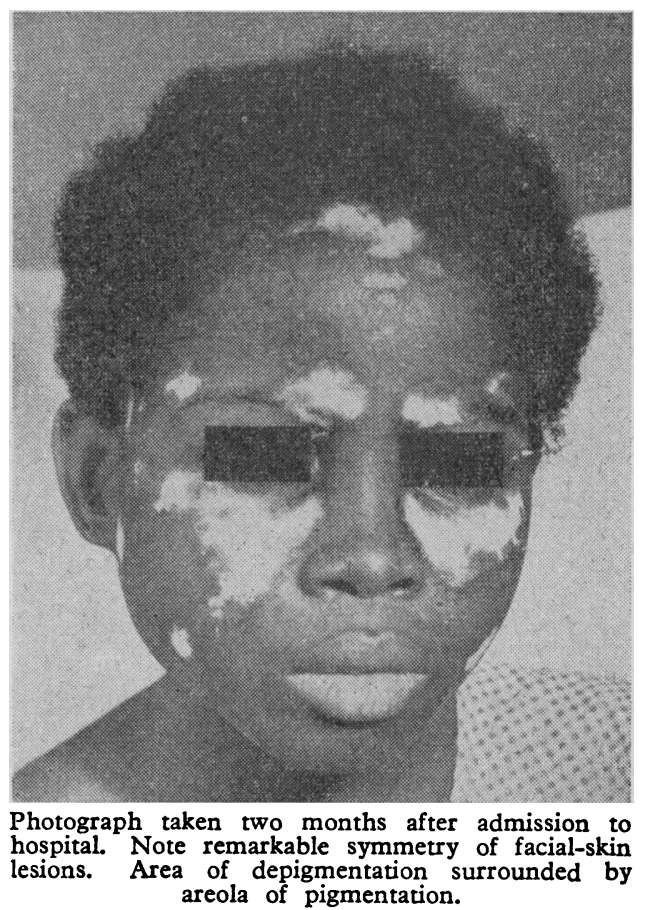

She left hospital four months after admission without having had a blood transfusion or any further crises. The scars were beginning to ke pigmented from without inwards. A skin biopsy specimen from the edge of a healed scar was reported to be within normal limits. The liver was not now palpable, but the spleen was just palpable and there was no trace of the lymphadenopathy.

\section{Discussion}

Winsor and Burch (1945) were right to term sickle-cell anaemia "a great masquerader." Skin lesions apart, this 16year-old girl presented with the hall-marks of acute lymphatic leukaemia-namely, epistaxis, anaemia, fever, generalized lymphadenopathy, and hepatosplenomegaly. The variability 
of the presenting symptomatology of sickle-cell disease needs to be emphasized, especially in a country like Britain, where the incidence of the condition is likely to increase, not decrease.

Intractable epistaxis has been described (Mabayoje, 1956 ; Hook and Cooper, 1958), but never in association with such symmetrical facial-skin scarring. Cornbleet et al. (1949) reported the cases of three male patients, aged 5 to 25 years, with sickle-cell anaemia who had a peculiar type of alopecia limited to the lateral parts of the scalp in a somewhat symmetrical pattern. The loss of hair in this area was intensified by crises. Paterson and Sprague (1959) described the case of a 15-year-old negro girl who suffered loss of hair from scalp and forearms during crises, the hair growing again during remissions. The only way I could explain the present case was to assume that extreme peripheral vasoconstriction took place in the face "in sympathy" for the blood loss through the nose. Such vasoconstriction was severe enough to cause skin necrosis. I prefer this explanation to the rather obvious one that the facial ulcerations were due to a thrombotic phenomenon, and for these reasons: (1) the remarkable symmetry of the lesions makes it difficult to believe that sickled erythrocytes were so correctly sequestrated; and (2) the girl denied using ice compresses or other mechanical applications to the face. Margolies (1951) pointed out that ulcers may follow trauma, or appear spontaneously, or follow infection.

\section{Summary}

Symmetrical facial-skin ulceration associated with severe epistaxis is described for the first time in sickle-cell anaemia.
It is suggested that extreme reflex vasoconstriction in the skin of the face precipitated skin necrosis. The variability of the presenting symptoms in sickle-cell disease is underlined.

I am grateful to Dr. S. R. A. Dodu, Physician-Specialist and Head of the Department of Medicine, Ghana Medical School, under whom the patient was admitted, for allowing me to publish the case.

\section{REFERENCES}

Cook, J. E., and Meyer, J. (1915). Arch. intern. Med., 16, 644.

Cornbleet, T., Schorr, H. C., and Barsky, S. (1949). Arch. Derm. Syph. (Chic.), 59, 519.

Corrigan, J. C., and Schiller, I. W. (1934). N. Engl. F. Med., 210, 410.

Cummer, C. L., and LaRocco, C. G. (1940). Arch. Derm. Syph. (Chic.), $42,1015$.

Herrick, J. B. (1910). Arch. intern. Med., 6, 517.

Hook, E. W., and Cooper, G. R. (1958). Sth. med. F. (Bgham, Ala.), 51, 610

Huck, J. G. (1923). Fohns Hopk. Hosp. Bull., 34, 335.

Hughes, J. G., Diggs, L. W., and Gillespie, C. E. (1940). F. Pediat., 17, 166.

Mabayoie, J. O. (1956). Brit. med. F., 1, 194.

McGavack, T. H., and Nussbaum, C. C. (1942). Urol. cutan. Rev., 46, 194.

Margolies, M. P. (1951). Medicine (Baltimore), 30, 357.

Mason, V. R. (1922). F. Amer. med. Ass., 79, 1318.

Ormsby, O. S., and Montgomery, H. (1954). Diseases of the Skin, 8th ed. Kimpton, London.

Paterson, J. C. S., and Sprague, C. C. (1959). Ann. intern. Med., 50, 1502.

Steinfield, D. E., and Klauder, J. V. (1927). Med. Clin. N. Amer., 10, 1561 .

Washburn, R. E. (1910-11). Virginia med. (Semi-)Mth., 15, 490.

Winsor, T., and Burch, G. E. (1945). 7. Amer. med. Ass., 129, 792.

Wintrobe, M. M. (1951). Clinical Hematology, 3rd ed. Lea and Febiger Philadelphia.

\section{Preliminary Communications}

\section{Prevention of Gastric Inflation During Neonatal Respiratory Resuscitation}

Brit. med. F., 1965, 2, 860-861

In a previous report (Williams and Beasley, 1964) we showed that simple mouth-to-mouth resuscitation was of no value in newborn lambs with atelectatic lungs, for it was observed that this method caused the stomach to distend before the lungs began to expand, and this is a complication that causes difficulties in the establishment of respiration. We concluded that the results of those experiments, though performed on stillborn lambs, could be applied to the newborn human child.

Where facilities for endotracheal intubation exist and the attendants possess the necessary skill and experience, the mouth-to-mouth method has nothing to commend it in dealing with a newborn infant who has not attempted respiration, but, because of lack of experience, not all practitioners, and few midwives, are skilled in introducing an endotracheal tube.

If distension of the stomach, which is the major drawback of the mouth-to-mouth method, could be prevented, the lungs would expand more quickly and at a lower pressure. A cuffed gastric tube was therefore devised to be passed down the oesophagus, and by inflating the cuff the oesophagus would be blocked, thus preventing air entering the stomach. There are two important reasons for using a gastric tube : (1) midwives are experienced in passing such a tube, and (2) emptying of the stomach is an important step in resuscitation of the newborn.

The tube used for lambs consists of $40 \mathrm{~cm}$. of $5 \mathrm{~mm}$. outside diameter plastic tubing (Fig. 1, AB). Its distal end ( $\mathrm{B}$ ) is occluded, but there are two small holes in the last $5 \mathrm{~cm}$. Fused to this tube is a very narrow-bore tube $1.5 \mathrm{~mm}$. outside diameter (C). This narrow tube has a wide opening (D) which fits a Luer type syringe (Fig. 2), and $2.5 \mathrm{~cm}$. distally it enters a small balloon (E). At $8 \mathrm{~cm}$. from the end of the main tube the narrow tube ends in another balloon $2.5 \mathrm{~cm}$. long $(F)$ which completely surrounds and is welded to the main tube. When a syringe is fitted to the mouth of the narrow tube and air is injected the proximal and distal balloons will distend. A small cap (G) is incorporated to close the opening of the narrow tube so that the syringe may be removed without loss of air from the balloons. The proximal end of the gastric tube (A) is also wide enough to fit a Luer type syringe in order to empty the stomach.

\section{EXPERIMENTS}

The method that we reported previously (Williams and Beasley, 1964) was again used, but in this series the cuffed gastric tube was employed. This was passed blind, and no difficulty was experienced in passing it.

Fourteen stillborn and five neonatal dead lambs were used, and the experiments were performed within 24 hours of death. 